\title{
A new metalinguistic degree morpheme *
}

\author{
M. Ryan Bochnak \\ University of California, Berkeley \\ Eva Csipak \\ University of Göttingen
}

\begin{abstract}
In this paper, we discuss and analyze ...ish/-ish in three of its uses: as a modifier of gradable adjectives; as a clause-final particle that hedges on a speaker's degree of commitment to a proposition; and as a general precision-regulator. In each case, ... ish/-ish makes reference to a degree that is slightly less than the standard for the constituent it applies to. We propose that proposition-modifying ...ish belongs to the class of metalinguistic degree morphology alongside metalinguistic comparisons, which have received recent attention in the literature (e.g., Giannakidou \& Yoon 2011; Morzycki 2011). We argue for a unified analysis of ...ish/-ish as a degree modifier, where the relevant degree variable can be provided lexically, or through a type-shifting operation that makes available a degree of precision in the sense of Morzycki (2011). This study has implications for research on the semantics of metalinguistic degree morphology, imprecision, speaker-oriented phenomena, and the role of subjectification in semantic change.
\end{abstract}

Keywords: ...ish/-ish, metalinguistic degree morphology, imprecision, hedges

\section{Introduction}

In this paper we discuss and analyze the use of ...ish as a sentence-final particle as in (1), which is especially prevalent among younger speakers of English. It appears at the end of a sentence, following a pause, which we represent orthographically with an ellipsis. We argue that it is part of a paradigm of metalinguistic degree morphemes. Roughly, in using ...ish, the speaker signals that she is not wholly committed to the truth of the proposition that it occurs with. This morpheme also comes in an 'ordinary' variety as the suffix -ish, where it occurs with gradable adjectives as in (2), and also as an adjectivizing derivational morpheme on nouns, as in (3).

* We thank the participants at SALT 24, particularly Elizabeth Bogal-Allbritten, Scott AnderBois, Nick Fleischer, Daniel Duncan, Julia Goldsmith-Pinkham, Chris Kennedy, Peter Klecha, and Stephanie Solt, as well as Andrea Beltrama, Kai von Fintel, and Judith Tonhauser for insightful feedback on this project. All remaining errors are our own.

C2014 Bochnak and Csipak 
A new metalinguistic degree morpheme

(1) PROPOSITIONS:
a. I liked the movie ... ish.
b. Lee drew a circle ... ish.
c. They won the match ...ish.

(2) GRADABLE ADJECTIVES:

a. Sam is tallish.

b. The dishes are dry-ish.

c. That color is blue-ish. ${ }^{1}$

(3) NOUNS:

a. He opened the gifts with childish delight. ${ }^{2}$

b. The cake has a coffee-ish flavor.

That there is such a metalinguistic degree morpheme should not come as a surprise given the existence of metalinguistic comparatives, which have received recent attention in the literature (e.g., Giannakidou \& Stavrou 2009; Giannakidou \& Yoon 2011; Morzycki 2011). This literature has highlighted both the similarities and differences between metalinguistic and 'ordinary' comparatives (4), which operate over propositions and gradable predicates, respectively, while sharing a common semantic core of comparison.

a. Your problems are more financial than legal.

METALINGUISTIC COMPARATIVE (McCawley 1998)

b. Kim is taller than Lee.

'ORDINARY' COMPARATIVE

We propose that the different uses of ...ish/-ish likewise have a semantic core common to its metalinguistic and 'ordinary' uses. ${ }^{3}$ In all cases, ... ish/-ish identifies a degree that is slightly less than the standard for the constituent it applies to. As such, it is a degree operator across all its uses. Since it can apply to a variety of linguistic expressions, its semantic type is flexible, although in every case its type is of the form $\langle\langle d, \alpha\rangle, \alpha\rangle$, where $\alpha$ is a variable for a semantic type. The degree variable for ...ish/-ish can come from one of two sources: while the suffix -ish can target a scale lexically encoded in a gradable adjective, propositional ... ish targets a scale of precision in the sense of Morzycki (2011). Under this view, the sentence in (1a) can be paraphrased roughly as "I am being less than fully precise when I say

1 Source: urbandictionary.com

2 Source: merriam-webster.com

3 We unfortunately will not be able to provide an analysis for -ish applied to nouns as in (3), and we are unsure whether a fully unified analysis is possible. This issue must be left for future research. 
that I like the movie." The attenuating effect of propositional ...ish then derives from a weakening of the level of precision with which an assertion is made. We will make this analytical intuition more precise (pun intended) later on. We will show that there are other suffixal uses of -ish that also target a scale of precision. In the case of gradable adjectives, -ish says that a property holds of an individual to a degree slightly less than the standard degree for that adjective.

This paper proceeds as follows. In section 2 we briefly outline our analysis for the suffixal version of $-i s h$ that attaches to gradable adjectives, largely following Sugawara (2012). Then in section 3 we outline the core of our analysis of ...ish/ish couched within Morzycki's (2011) analysis of metalinguistic comparison as manipulating degrees of imprecision. Using this framework allows us to capture the notion of attenuating speaker commitment in terms of imprecision. It also provides a straightforward account of the relation between metalinguistic and ordinary uses of ...ish/-ish, as well as a basis for precision-based uses of suffixal -ish. In section 4 we compare this approach to that of Giannakidou \& Yoon (2011) in terms of speaker preference. In the remainder of the paper, we compare metalinguistic ... ish with other linguistic expressions that appear to have a semantic function similar to metalinguistic ... ish: in section 5 the modifier sorta (Anderson 2013); in section 6 German modal particle schon (Zimmermann 2014); and in section 7 sentence-final ...NOT in English (Horn 1989). Section 8 concludes.

\subsection{The distribution and uses of ...ish/-ish}

Before going on to the analysis, we briefly discuss further distributional facts and previous literature on ...ish/-ish in the remainder of this section. As we have already seen, ... ish/-ish can appear with propositions, gradable adjectives, and nouns. Morris (1998) observes that the suffix can also appear with proper names to form adjectives, and that like in its other uses it has an attenuating effect here as well. In comparing the interpretation of -ish with the suffix -esque, she notes, "a Kafkaish situation would not seem as nightmarish as a Kafkaesque one" (Morris 1998: 212). ${ }^{4}$ As shown in (5), it can also occur with temporal expressions such as at 3 and since phrases. In these uses, the speaker is being explicit that s/he is being less than fully precise in identifying these times.

a. Let's meet at Starbucks at 3-ish.

b. I've known what they are since high school-ish. ${ }^{5}$

c. I haven't dreamt about her like that since I found out about you two ... ish. ${ }^{6}$

4 Note that this quote also exemplifies another case of adjectivizing -ish applied to a noun.

5 Source: Facebook status

6 Source: Friends season 5 episode 16 
A new metalinguistic degree morpheme

As evidenced by the examples in (1) and (5c), and as indicated by our use of an ellipsis in its orthographic rendering, propositional ...ish has developed from being a bound suffix to an unbound morpheme. Further evidence for its status as an unbound morpheme comes from (6), where ...ish stands alone as the answer to a question.

(6) Mac: You've got a plan, right?

Veronica: .... ish. ${ }^{7}$

Given this trajectory, ... ish is one of the few attested cases of degrammaticalization (Kuzmack 2007; Norde 2009), whereby a linguistic item develops from a bound grammatical affix to a free word.

We also note here that the contribution of propositional ...ish is typically speaker-oriented, in that its attenuating flavor reports on a subjective judgment of the speaker. Like other more familiar speaker-oriented elements, it resists embedding under negation and if clauses, as shown in (7)-(8). However, it can be embedded under reportative or attitude predicates, as in (9), in which case the subjective judgment can be shifted to the matrix attitude holder. ${ }^{8}$

(7) I didn't like the movie ...ish.

$\neq$ 'It's not the case that [I liked the movie ... ish].

(ish $>\neg)$

(8) ??If Lee draws a circle ... ish, he will get a gold star.

(9) Lee $\{$ told me/believes $\}$ that Kim liked the movie ... ish.

With this background in place, we now turn to our analysis of ...ish/-ish, beginning with what we term as 'ordinary' -ish.

\section{Ordinary -ish}

As our first order of business, we present an analysis of the version of -ish that attaches to gradable adjectives. In this environment, -ish says that the degree to which an individual holds a property is less than the standard for the gradable adjective it applies to. We follow the insights of Sugawara 2012, which is the only analysis of -ish we are aware of that is couched within a formal semantic framework. Sugawara observes that like other degree adverbs such as very and completely, -ish shows sensitivities to scale structure. Specifically, $-i s h$ is restricted to adjectives whose scales are either unbounded (open) or contain a maximum value (upper

7 Source: Veronica Mars season 2 episode 8

8 Note that (9) also admits a speaker-oriented reading where the speaker attenuates on Lee's belief. 
bound), but is marked with adjectives whose scales contain a minimum value (lower bounded), as shown in (10). ${ }^{9}$

(10) a. Sam is tallish.

OPEN SCALE

b. The room is clean-ish.

UPPER BOUND SCALE

c. ??The rod is bent-ish.

LOWER-BOUND SCALE

Given these distributional facts, it is natural to give an analysis for -ish modeled after the analysis for other degree adverbs. Following an influential line of work, we treat gradable adjectives as relations between individuals and degrees, namely type $\langle d,\langle e, t\rangle\rangle$ (Cresswell 1976; Heim 2001; Kennedy \& McNally 2005). A denotation for tall is thus given in (11):

$$
\llbracket t a l l \rrbracket=\lambda d \lambda x \text {.height }(x) \succeq d
$$

Under this view, the role of degree morphology, including degree adverbs, is to bind the degree argument and specify something about its value. In this case, -ish applies to a gradable adjective and returns a property that holds of an individual to a degree that is close to, but somewhat less than, the standard degree for the adjective (Sugawara 2012). We implement this idea formally by using a context-sensitive predicate small, which is true of a degree if it counts as 'small' in a given context. In our case, the degree measured by small is the difference between the standard degree for the gradable predicate and the maximal degree to which an individual holds the relevant property. ${ }^{10}$ That is, small simply restricts the degree to which the individual holds the relevant property from being too low. This seems to be what -ish indeed requires; for instance, (10a) cannot be used if Sam is in fact quite short. Our semantics for adjectival - $i$ sh is thus given in (12), following Kennedy \& McNally's (2005) general template for the semantics of degree adverbs, where $d_{s}$ is the standard degree for the gradable adjective. This denotation also makes use of a maximality operator over degrees (Rullmann 1995).

$$
\llbracket-i s h \rrbracket^{c}=\lambda P_{\langle d, e t\rangle} \lambda x . \max \{d \mid P(d)(x)\} \prec d_{s} \wedge \operatorname{small}_{c}\left(d_{s}-\max \{d \mid P(d)(x)\}\right)
$$

In prose, -ish is a function that takes a gradable predicate meaning and returns a property that is true of an individual $x$ if the degree to which the gradable predicate holds of $x$ is slightly less than the standard for the gradable predicate.

This analysis can explain why -ish is odd with adjectives that have lowerbounded scales. What -ish asserts is that the degree to which an individual holds a property is below the standard for that adjective. For open scale adjectives, this

9 See Kennedy \& McNally (2005) and Rotstein \& Winter (2004) for tests distinguishing the scale structure of gradable adjectives.

10 This predicate small is modeled after a similar predicate large introduced by Morzycki (2012). 
A new metalinguistic degree morpheme

is a vague relative standard, and for an upper bounded adjective it is the maximal degree on the scale, i.e., the upper bound (Kennedy 2007). So -ish is looking for a degree that is slightly less than a relative or maximal degree. However, adjectives with lower bound scales have a default minimum standard, i.e., the lower bound. But if the standard is the minimum degree on the scale, then there is no degree below the standard, ruling out -ish with adjectives with lower bound scales.

An outstanding puzzle noted by Sugawara is that the anomaly of -ish with minimum standard adjectives is not categorical, as would be predicted under this analysis. There are contexts where such collocations seem more natural, and also certain minimum standard adjectives combine more easily with -ish than others. For instance, she reports that using bent-ish to describe someone's nose is more acceptable than using it to describe a stick that is slightly bent. We claim that the acceptable collocations of minimum standard adjectives with -ish are actually cases of -ish targeting a scale of precision, rather than the scale lexically encoded in the gradable adjective itself. We likewise will be able to account for uses of -ish with temporal adverbs in this way, such as those in (5). In those cases, the relevant interpretation of -ish is roughly "around the threshold" (i.e., the time named by the adverb), rather than "below the threshold" as would be predicted by the analysis in (12). To see how this idea would work, we will have to first introduce our analysis of propositional ...ish, which we claim always tracks a scale of precision. We turn to this now in the next section.

\section{Metalinguistic degree morphemes and scales of precision}

We claim that propositional ...ish is a member of the paradigm of metalinguistic degree morphemes in English, alongside metalinguistic comparatives. Our analysis of ...ish is based on a recent analysis of metalinguistic comparison by Morzycki (2011). According to Morzycki, metalinguistic comparison involves comparing degrees of precision. Under this view, the metalinguistic comparative in (13a) can be paraphrased as in (13b).

(13) a. Your problems are more financial than legal.

b. "It is more precise to say that your problems are financial than it is to say that your problems are legal."

This idea is implemented formally as follows. Morzycki proposes that the interpretation of linguistic expressions is relativized to a degree $d$ of precision. The scale of precision is modeled as a set of degrees corresponding to the real numbers in the interval $[0,1] .{ }^{11}$ Morzycki implements his analysis within an alternative

11 Note that this scale is construed as being a closed set of degrees. This property (in particular, the fact that the upper bound in included in the set) will be important for us later). 
semantics (Hamblin 1973; Rooth 1992). ${ }^{12}$ The interpretation of the expression three o'clock is thus modeled as in (14), where $\approx_{d, c}$ is a similarity relation defined in (15).

$\llbracket$ three o'clock $\rrbracket^{d, c}=\left\{t_{i}: t \approx_{d, c} 3: 00\right\}$

(15) $\alpha \approx_{d, c} \beta$ iff, given the ordering imposed by the context $c, \alpha$ resembles $\beta$ to (at least) the degree $d$, and $\alpha$ and $\beta$ are of the same type (Morzycki 2011: 51)

Thus, three o'clock denotes the set of alternatives (in this case, times) that are at least $d$-similar to 3:00 in $c$. When $d=1$ (i.e., the maximal degree of precision), 『three $o^{\prime}$ clock $\rrbracket^{1, c}$ denotes the singleton set $\{3: 00\}$. When $d=0$ (minimal precision), $\llbracket$ three o'clock $\rrbracket^{0, c}$ denotes the set of all times in the domain.

All 'ordinary' expressions are interpreted in this way. Linguistic expressions that are 'metalinguistic' directly manipulate the precision parameter $d$. In order to do this, Morzycki introduces PREC as a mechanism that makes the degree of precision available by lambda abstracting over it, as in (16).

$$
\llbracket \operatorname{PREC} \alpha \rrbracket^{d}=\lambda d^{\prime} . \llbracket \alpha \rrbracket^{d^{\prime}}
$$

The application of PREC is essentially what makes an expression metalinguistic, in that it makes one of the parameters of interpretation available for manipulation. In the case of gradable adjectives, PREC applies to the positive form, i.e., after the application of POS, which introduces the standard (see, e.g., Cresswell 1976; von Stechow 1984; Kennedy \& McNally 2005).

Morzycki's denotation for metalinguistic more is then given in (17). It takes two 'precisified' properties $g$ and $f$ and returns the (singleton) set of alternatives consisting of a property of individuals $x$ such that there exists a degree of precision $d^{\prime}$ to which $x$ is $g$ is true and $x$ is $f$ is not. ${ }^{13}$

$$
\begin{aligned}
& \llbracket m o r e_{M L} \rrbracket^{d}=\lambda g_{\langle d,\langle e, s t\rangle\rangle} \lambda f_{\langle d,\langle e, s t\rangle\rangle}\left\{\lambda x \lambda w . \exists d^{\prime}\left[g\left(d^{\prime}\right)(x)(w) \wedge \neg f\left(d^{\prime}\right)(x)(w)\right]\right\} \\
& \text { (Morzycki 2011: 65) }
\end{aligned}
$$

The truth conditions that arise as a result of this meaning parallel a fairly widespread analysis of the semantics of ordinary comparatives (see e.g., Schwarzschild 2008). The main difference is that ordinary comparatives track degrees of the scales encoded in gradable adjectives, whereas metalinguistic comparatives only track degrees of precision made available by PREC.

12 See Lasersohn 1999 for an analysis of imprecision in terms of 'pragmatic halos.'

13 Our exposition here glosses over many of the compositional details of metalinguistic comparatives; for

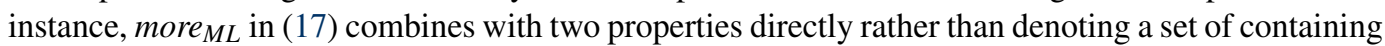
the relevant function, as might be expected within alternative semantics. We refer interested readers to Morzycki's paper for these details. 
A new metalinguistic degree morpheme

With these mechanisms for metalinguistic degree morphology in place, it is now straightforward to combine them with the analysis of ordinary -ish in the previous section to arrive at the semantics for metalinguistic ...ish. Recall the intuition we are trying to account for: this use of ... ish says that the degree to which the speaker is committed to a proposition $p$ is less than maximal. Another way of putting it, which is more in-line with the framework we are adopting, would be the following paraphrase: when a speaker utters a sentence of the form "...ish $(p)$," she is saying "I am being less than fully precise when I say that $p . "$

We implement this within the present framework as follows. We assume that Morzycki's PREC can apply to propositions of type $\langle s, t\rangle$ to transform them into type $\langle d,\langle s, t\rangle\rangle$ propositions with the degree of precision available for binding metalinguistic degree morphemes (see (16)). Our proposal is that ...ish is such a morpheme, and has the semantics in (18). ${ }^{14}$

$$
\left.\llbracket \ldots i s h \rrbracket^{d, c}=\lambda p_{\langle d,\langle s, t\rangle\rangle \cdot\{\lambda w \cdot \max }\left\{d^{\prime} \mid p\left(d^{\prime}\right)(w)\right\} \prec d \wedge \operatorname{small}_{c}\left(d-d^{\prime}\right)\right\}
$$

Comparing (18) with the semantics for ordinary -ish in (12), we see that the general contribution of both versions of ...ish/-ish is parallel. Both require a degree that is less than the standard degree for the relevant scale. Whereas for ordinary -ish the scale comes from the gradable adjective, for metalinguistic ... ish the scale is always one of precision, made available by PREC.

We assume that ...ish is licensed in this metalinguistic use because the scale of precision is by hypothesis an upper-bound scale. Recall from the previous section that ordinary -ish requires an open or upper-bound scale to be licensed. Morzycki makes the assumption about the upper-boundedness of the scale of precision without much argument, and indeed, given Grice's (1975) maxim of Quality, by which speakers only say what they believe to be true and have good evidence for, it seems right to think of the scale of precision as including an upper bound, and further that the standard $d_{s}$ for this scale is that upper bound. ${ }^{15}$ Given Kennedy's (2007) theory that adjectives whose scales include scalar endpoints will have standards that default to those endpoints, the connection between metalinguistic expressions and the nature of the scale of precision becomes clearer.

We now return to two outstanding cases that were problematic for Sugawara's analysis of -ish, namely the acceptability of -ish with some adjectives with lowerbound scales, and with temporal adverbs such as (5). We propose that these are

14 To fully implement our proposals consistently within the framework of alternative semantics, we need to modify our semantics for -ish in (12) to reflect this. We leave it up to the reader to take this step.

15 Conflicts with other maxims may require speakers to be less than fully precise in some, if not many, contexts. The level of precision used in a given context also depends on the level of granularity made available or at issue in a given context; see Krifka 2009 and Cummins, Sauerland \& Solt 2012 for more on contextual granularity and efficient communication. 
in fact uses of precision-regulating -ish. This use of -ish combines directly with a precisified property (i.e., where PREC has applied to a property) rather than at the propositional level. Our evidence for this comes from our intuitions regarding the phonology of -ish versus ...ish: while propositional ...ish is always accompanied by a preceding pause, ordinary -ish and the use of precision-regulating -ish as applied to properties have the phonology of a bound morpheme.

Recall the problem for the analysis of ordinary -ish with lower-bound adjectives such as open. The analysis in section 2 predicts that such combinations should be unacceptable, since -ish states that an individual holds a property to a degree lower than the standard. Since lower-bounded adjectives have standards that coincide with the minimal scale value, there are no values on the scale that are lower than the standard. And indeed as noted by Sugawara, many uses of -ish with lower-bound adjectives are degraded, e.g., (10c). But as we have seen, there are cases where -ish can combine with lower-bound adjectives without being degraded (e.g., a bent-ish nose). We propose that these cases actually involve an intermediate variant between ordinary and propositional ...ish/-ish: a precision-regulating -ish that applies directly to properties where the precision degree variable has been made available by PREC. The semantics of this version of -ish, which we will call -ish $h_{p r e c}$, is given in (19).

$$
\llbracket-i s h_{\text {prec }} \rrbracket^{d, c}=\lambda g_{\langle d,\langle e, s t\rangle\rangle} \cdot\left\{\lambda x \lambda w \cdot \max \left\{d^{\prime} \mid g\left(d^{\prime}\right)(x)(w)\right\} \prec d \wedge \operatorname{small}_{c}\left(d-d^{\prime}\right)\right\}
$$

This version of -ish is not subject to any restrictions based on the scale structure of the adjective it combines with. As before with ...ish, the scale being targeted is the scale of precision, which is an upper-bound scale. This means that it can combine with adjectives with lower-bound scales with no problem. ${ }^{16}$

We propose a parallel explanation for -ish with temporal adverbs such as (5). In these cases, the problem was that -ish is not restricted to lower values on a scale (i.e., earlier times), but is compatible with a 'halo' of times surrounding the relevant time. Our proposal here is that $-i s h_{\text {prec }}$ is at work here as well. Making the simplifying assumption that such adverbs denote times, as in (14), we propose that $-i s h_{\text {prec }}$ takes a 'precisified' time as its argument (type $\langle d, i\rangle) .{ }^{17}$ In lowering the standard of precision on times, it allows for a halo of times surrounding the relevant time (i.e., we can be imprecise in either direction).

We close this section by making a few comments on the speaker-oriented nature of ...ish, as shown in section 1.1. It is worth noting that there is nothing about

16 More still needs to be said in order to explain Sugawara's observation that -ish cannot freely combine with all minimum-standard gradable adjectives, and why bent-ish seems more acceptable in describing someone's nose rather than a nail. We do not have an explanation for these facts at this time, though we suggest this may have to do with pragmatic and contextual factors that go into a speaker's choice to use a hedging expression.

17 The details of the denotation in terms of the form of the alternatives in the alternative set would also have to be altered to reflect this change; we leave the task of fleshing out the details for future work. 
A new metalinguistic degree morpheme

Morzycki's system that directly associates metalinguistic degree morphemes with speaker-orientation. But there is a sense in which propositional ...ish and -ish prec can be said to be speaker-oriented indirectly. We argued that the contribution of ...ish and -ish $h_{\text {prec }}$ is to explicitly signal that the speaker is lowering the level of precision being used in making a claim. Given that speakers are by default assumed to be relatively precise by the Maxim of Quality, the use of ...ish or -ish $h_{\text {prec }}$ is a deliberate action by the speaker to convey that she is being less than precise. This move is thus inherently speaker-oriented, although in cases with true embedding such as (9), the speaker-oriented aspect of the meaning shifts to the matrix attitude holder. In this connection, we note that certain uses of totally in English have been argued to be another case of speaker-oriented precision manipulation (Beltrama 2014; also see McCready \& Kaufmann 2013). Whereas ...ish/-ish prec $_{\text {signals a }}$ lowering of precision, totally reinforces that the speaker is using the highest possible degree of precision in making a claim. Thus, there is potentially a deeper connection lurking here between these metalinguistic, precision-manipulating morphemes, and speaker-oriented meanings. ${ }^{18}$

\section{Metalinguistic comparison as a preferential attitude}

In this section we compare our analysis with an alternative couched within a framework that treats metalinguistic comparison not as comparing degrees of imprecision, but rather as involving an epistemic attitude of preference towards a proposition or sentence (Giannakidou \& Stavrou 2009; Giannakidou \& Yoon 2011).

At the heart of this analysis is the idea that metalinguistic comparison (and by extension other metalinguistic degree morphology, and also metalinguistic negation) expresses a speaker's attitude about the appropriateness of an utterance or sentence. Giannakidou \& Stavrou and Giannakidou \& Yoon make use of an individual anchor or epistemic agent $\alpha$ who provides the epistemic judgment. By default, $\alpha$ is the speaker of the utterance, but can be shifted to the subject of an attitude predicate (recall (9) in section 1.1). The idea is that $\alpha$ holds a gradable attitude $R$ towards a sentence to a degree $d$. In metalinguistic comparison, the degrees to which $\alpha$ holds that attitude towards two sentences are compared. The value of the relevant attitude $R$ ranges from desirability, belief, preference, or willingness to assert a proposition; in the later work, Giannakidou \& Yoon treat $R$ uniformly as an attitude of preference. Under this view, the truth conditions of the metalinguistic comparative in (13a) could be paraphrased as " $\alpha$ prefers to say that your problems are financial, rather than to say that they are legal," or " $\alpha$ is more willing to assert that your problems are financial, rather than that they are legal." The semantics for metalinguistic more ${ }_{M L}$

18 To be sure, not all cases of slack regulators have speaker-oriented meanings, for instance all, perfectly discussed by Lasersohn (1999). 
under this view is given as in (20): ${ }^{19}$

$$
\llbracket \text { more }_{M L} \rrbracket^{c}=\lambda p_{\langle s, t\rangle} \lambda q_{\langle s, t\rangle} \cdot \exists d[R(\alpha)(p)(d) \wedge \neg R(\alpha)(q)(d)]
$$

In prose, there is a degree $d$ to which $\alpha$ holds the attitude $R$ to $p$, and to which $\alpha$ does not hold the attitude $R$ to $q$.

An analysis of ...ish could be implemented under this framework in the following way: the degree to which $\alpha$ is willing to assert $p$ is less than maximal. Using similar tools as in (18), the semantic contribution of ...ish under this view is given as in (21). Again, we assume that the standard degree $d_{s t d}$ for $R$ is (near) maximal for rational conversational participants.

$$
\llbracket \ldots i s h \rrbracket^{c}=\lambda p_{\langle s, t\rangle} \cdot \max \left\{d^{\prime} \mid R(\alpha)(p)\left(d^{\prime}\right)\right\} \prec d_{s t d} \wedge \operatorname{small}_{c}\left(d_{s t d}-d^{\prime}\right)
$$

Thus, an analysis of ...ish can be made to work with both Morzycki's and Giannakidou \& Stavrou/Giannakidou \& Yoon's theories of metalinguistic comparison. However, there are at least three reasons to prefer the analysis based on imprecision given in the previous section, rather than the one based on a propositional attitude. First, the nature of the propositional attitude is left vague on the latter account. This is seen as a positive feature of the analysis according to Giannakidou \& Yoon, since a speaker can prefer a sentence for a variety of reasons, depending on the conversational goals in a particular context. But it seems that $R$ is too underspecified under this view. For example, a speaker might prefer a sentence because it contains more sibilants than another sentence, and indeed it might be one of the conversational goals to come up with sentences containing many sibilants, say for constructing a homework problem for Linguistics 101, but even in such a context, a metalinguistic comparative like (22a) isn't possible (compare with (22b), which periphrastically asserts Giannakidou \& Yoon's analysis, and which is more acceptable in this context). ${ }^{20}$
a. ?? She sells sea shells by the seashore more than Bob went to Oakland.
b. I prefer the sentence 'She sells sea shells by the seashore' more than the sentence 'Bob went to Oakland'.

Thus, it seems that we need a more narrow definition of what it means to be metalinguistic, and in this regard we follow Morzycki by claiming that metalinguistic

19 We have slightly altered the semantics given by the authors to make the comparison to Morzycki's metalinguistic more $_{M L}$ in (17) more transparent. We should also say that (20) is closer to Giannakidou \& Stavrou's (2009) implementation rather than that of Giannakidou \& Yoon (2011).

20 Note that Giannakidou \& Yoon (2011) distinguish between attitudes of preference towards propositions versus towards sentences; see their paper for arguments for making this distinction. 
A new metalinguistic degree morpheme

degree morphemes have to do with imprecision rather than a general attitude of preference.

Second, it is unclear in what way having a propositional attitude towards a sentence counts as metalinguistic. As Giannakidou \& Yoon in fact point out, their analysis parallels Villalta's (2008) semantics for want, which is also argued to involve a gradable propositional attitude. It seems clear, however, that we wouldn't want to say that sentences containing want are metalinguistic in the way that metalinguistic comparatives are.

Finally, and most importantly, the analysis in terms of a propositional attitude cannot straightforwardly account for the other precision-based uses of -ish. We have argued that outside of the metalinguistic use, there are certain cases where -ish clearly involves targeting a scale of precision, in particular when -ish combines with gradable adjectives with lower-bounded scales, and with temporal expressions like 3 o'clock (see (5)). Our analysis in the previous section can easily handle such cases without modifying the general contribution of ...ish/-ish across uses, whereas it is less clear how to extend the semantics in (21) to such cases.

One argument Giannakidou \& Yoon give against Morzycki's analysis is that his more $_{M L}$ compares properties (see (17)), whereas those authors have the intuition that more $_{M L}$ should compare propositions. But this is not an essential property of Morzycki's analysis. In fact, PREC can in principle apply freely to make the degree of imprecision available for any constituent, and indeed it must apply to propositions at least sometimes in order for our analysis to go through. Morzycki in fact shows there are "clausal" metalinguistic comparatives where PREC must apply to propositions, such as (23). In these cases, PREC must apply to the clausal constituent following than.

a. Clarence is a syntactician more than [Herman is a semanticist].

b. George is afraid of Dick more than [David is fond of him]. (Morzycki 2011: 68)

So there appears to be variation in metalinguistic comparatives along the same parameter as we find with ordinary comparatives, namely in whether they have phrasal or clausal standards (see Kennedy 1997 for discussion on this distinction in ordinary comparatives).

One place where the analysis in terms of a propositional attitude of preference may have an advantage over an imprecision-based one is in accounting for the speaker-oriented nature of ...ish, and, relatedly, the shifts of perspective when embedded under propositional attitudes (see (9)). The analysis of Giannakidou $\&$ Stavrou/Giannakidou \& Yoon makes use of an epistemic agent $\alpha$, which is the individual who provides the judgment upon which the comparison is based (i.e., the holder of the attitude $R$ ). By default, $\alpha$ is the speaker, but can shift to identify 
with a syntactic argument under embedding by a propositional attitude verb. While these authors are not explicit about the formal details about how such a shift occurs under embedding, this style of analysis makes explicit the source of the subjective judgment associated with ... ish and metalinguistic comparatives, something that the imprecision-based analysis can only do indirectly. At this point, we have nothing more to say about this issue beyond the comments we have already made at the end of section 3 regarding the relationship between precision regulation and speaker subjectivity. ${ }^{21}$ As we said there, this is an exciting research question that has begun to receive more attention recently (Beltrama 2014; McCready \& Kaufmann 2013), and we hope that future research will be devoted to uncovering any deeper connections that may exist between these linguistic domains.

\section{Comparison with sorta}

Let us now compare our analysis of ...ish with Anderson's (2013) analysis of the modifier sorta. Intuitively, both items serve as hedges for the category they apply to. As Anderson shows, sorta combines with gradable and non-gradable predicates alike, including adjectives, verbs and even some nouns, as shown in (24).

Cross-categorial modification with sorta (Anderson 2013: 82)
a. Gas is sorta expensive.
(gradable adjective)
b. ... running on concrete and accidentally sorta kicked the ground
(verb)
c. I may be your sorta mom now.
(noun)

Interestingly, Anderson does not mention any propositional use of sorta parallel with ...ish. Our own intuitions waver on the acceptability of the sentences in (25), though they do sound like they could plausibly be uttered in colloquial speech in order to achieve a hedging effect similar to the corresponding sentences with ...ish in (1). However, it seems very clear that those in (26) are unacceptable, indicating that to the extent that sorta has a propositional use, it is much more constrained than propositional ...ish..$^{22}$

(25) a. I liked the movie, sorta.

b. Lee drew a circle, sorta.

c. They won the match, sorta.

21 One way this might be implemented would be to make reference to a judge parameter as has been proposed for predicates of personal taste (Lasersohn 2005; Stephenson 2007).

22 A future experimental study with native speakers or more detailed corpus study is clearly in order here to tease apart any differences in acceptability, frequency, or meaning between ...ish and sorta in this environment. 
A new metalinguistic degree morpheme

a. ??I didn't like the movie, sorta.

b. ??If Lee draws a circle, sorta, he will get a gold star.

c. ??Lee $\{$ told me/believes $\}$ that Kim liked the movie, sorta.

As in our analysis of ...ish in section 3, Anderson proposes an analysis of sorta that binds a degree variable. For gradable adjectives like in (24a), the degree variable is provided by the lexical scale associated with the adjective. With non-gradable predicates, Anderson proposes that PREC first applies to make available a degree of imprecision, which sorta can then target. Thus, sorta can manipulate degrees of precision, just as we proposed for ... ish.

Setting aside the issue of whether or not sorta can combine with propositions as freely as ... ish, there is one feature of Anderson's analysis of sorta that distinguishes it from our analysis of ...ish/-ish. Namely, sorta simply requires a degree to be close to the standard, not strictly lower than the standard, as we have claimed for ...ish/-ish. His semantics for sorta is given in (27); note that the definition of $\lessdot$ in (28) is similar to our function small, except that it is non-committal as to which direction "closeness" comes from (it could be approaching the standard from above or below). 23

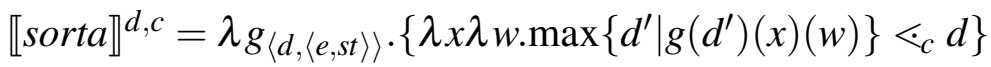

(28) $\forall d, d^{\prime}\left[d \lessdot_{c} d^{\prime}\right.$ iff the value of $d$ is close to $d^{\prime}$ as determined by the context $\left.c\right]$ (adapted from Anderson 2013: 90)

This difference accounts for the fact that, unlike -ish, sorta is perfectly acceptable with gradable adjectives with lower-bounded scales, with a regular degree reading. Recall that -ish is not acceptable in such cases, modulo a coerced precision reading; witness (29).

(29) This stick is sorta bent/??bent-ish.

In sum, sorta and ...ish/-ish intuitively have a similar hedging effect, although there are subtle distributional and interpretational differences between them. On the one hand, sorta is more constrained than ...ish/-ish in that sorta mainly applies to predicates, and propositional use is only available for a subset of those cases where propositional ...ish is licensed. On the other hand, sorta is acceptable with gradable adjectives with lower-bounded scales with a regular degree reading, while -ish is only possible with a precision reading. This latter difference is accounted for by the fact that the semantics of ...ish is looking for a degree that is strictly lower than a standard, ruling out minimum standards, while sorta is less picky in this respect:

23 We have altered certain aspects of Anderson's analysis in order to make clearer the comparison with ... ish/-ish. 
it looks for a degree that approaches a standard from above or below. We thus see variation in the distribution and interpretation of hedges that appear at first glance to contribute very similar meanings.

\section{Comparison with German schon}

We now turn to a comparison with the German modal particle schon, which is also felt to have a hedging effect according to native speakers. ${ }^{24}$ Like ... ish, this use of schon applies at the level of the proposition. According to Zimmermann (2014), it gives rise to an inference that although the proposition $p$ is true, there are also reasons to believe that $\neg p$. For instance, an utterance of (30) gives the impression that the speaker is about to follow up with reasons why St. Pauli might not in fact be considered a good team.

(30) St. Pauli ist schon ein gutes Team.

'St. Pauli IS a good team, but ...'

Furthermore, schon is not possible when the speaker is fully certain that the embedded proposition is true. As Zimmermann puts it, "In contexts with uncontroversial circumstances ... the use of schon $p$ would be misleading as it points to the existence of facts supporting not- $p$ " (p. 9), and thus the use of schon is used to indicate weakened commitment to $p$ on the part of the speaker. These descriptions of schon indeed make it look similar to the propositional use of ...ish.

However, Zimmermann argues that the hedging effect of schon is not asserted, but rather part of its not-at-issue content. Under his analysis, the sentence in (30) asserts that St. Pauli is a good team, but also conveys the not-at-issue content that there is more evidence for saying that St. Pauli is a good team than there is for saying they are not a good team. This distinction between the two levels of meaning is brought into focus by a difference in whether they can be directly challenged or not. As shown in (31), the asserted, at-issue content can be directly challenged, while the not-at-issue content cannot.

A: St. Pauli ist schon ein gutes Team.

B: No, that's not true! They are a lousy team!

$\mathrm{B}^{\prime}$ : ??No, that's not true! There are more reasons to think that they are good than that they are lousy.

(Zimmermann 2014: 2)

Also note that a response of That's not true! They are a really good team! to (31) is infelicitous, another point where schon differs from ...ish (see (32) below).

24 We ignore here the aspectual use of schon, translated as 'already'. See Krifka 2000 on the aspectual interpretation, and Zimmermann 2014 for a unified analysis of the two uses of schon. 
A new metalinguistic degree morpheme

Under our analysis, we have treated the hedging aspect of ...ish as part of its asserted content. This seems to be correct. In contrast with schon, it is possible to directly challenge the hedging aspect of the meaning of ...ish, as shown in (32).
A: The Blackhawks are a good team ...ish.
B: No, that's not true! They're awful!
$\mathrm{B}^{\prime}$ : No, that's not true! They're amazing!

In fact, our analysis predicts that both the $\mathrm{B}$ and $\mathrm{B}^{\prime}$ responses in (32) are possible. In the $\mathrm{B}$ response, what is being denied is that the degree of precision is lower than the standard degree. In the $\mathrm{B}^{\prime}$ response, what is being denied is that the degree of precision is close to the standard, to the extent that it is more appropriate to use an antonym. $^{25}$

Interestingly, Zimmermann also notes an affinity between schon and metalinguistic comparison. However, rather than considering them members of the same paradigm, he claims that the difference between them is that metalinguistic comparatives, formed in German with eher, assert the not-at-issue content of schon. Note that the denial in (33) is perfectly licit.

A: St. Pauli ist eher ein gutes Team als nicht.

'St. Pauli is more a good team than a bad team.'

B: That's not true! There are more negative than positive sides to the team! (Zimmermann 2014: 11)

Although it turns out that the interpretation of the German modal particle schon is quite different from that of ...ish, the comparison between the two is instructive, since it allows us to tease apart whether the hedging component of the meaning is at-issue or not-at-issue. For ...ish, it is part of the at-issue content, while for schon it is part of the not-at-issue content.

\section{Comparison with ...NOT}

We close out our survey of linguistic items that are in some sense comparable with ...ish/-ish by considering sentence-final ...NOT. Like ...ish, it occurs at the end of a sentence following a pause. It is often accompanied with a focus intonation. A couple of examples are provided in (34).

25 We note here that the use of predicates of personal taste in (31) and (32) may be having an effect on the results. Again, we believe that exploring the possible connections between the subjectivity found in ...ish and predicates of personal taste is worthy of further research. 
a. I liked the movie ... NOT.

b. I'm having a good time ... NOT. ${ }^{26}$

Although the form of ...ish and ...NOT are similar, their function is not. This use of ...NOT is used as a logical negation of a sentence, and thus is not metalinguistic. In (34a) what is being conveyed is that the speaker did not like the movie, and in (34b) that the speaker is not having a good time. By contrast, metalinguistic negation is used to object to some aspect of an utterance, including style, register, or phonetic realization; see (35).

(35) a. It's not stewed bunny, it's civet de lapin.

(Horn 1989: 370)

b. He didn't call the PÓLIS, he called the POLÍS.

(Horn 1989: 371)

Despite this difference in meaning, we speculate that propositional ...ish may have developed in part based on analogy with ...NOT. Interestingly, other distributional facts are shared between ...ish and ...NOT, including resistance to embedding under if clauses and attitude predicates; see (36). ${ }^{27}$

a. ??If Lee draws a circle ... NOT, he will get a gold star. (Intended: If Lee doesn't draw a circle, he will get a gold star.)

b. Lee believes that Kim liked the movie ... NOT. Not possible: Lee has the belief that Kim didn't like the movie. OK: Lee does not have the belief that Kim liked the movie.

Despite these distributional and phonological similarities, it appears that ...NOT and ... ish are not part of the same semantic class.

\section{Conclusion}

In this paper, we provided a semantic analysis of various uses of ...ish/-ish as a cross-categorial modifier. When the suffix combines directly with gradable adjectives, it receives an ordinary degree reading, indicating that the property holds of an individual to a degree somewhat less than the standard. As such, it is generally unacceptable with adjectives associated with minimum standards. We then analyzed propositional ...ish as a metalinguistic degree morpheme, which states that a speaker is less than fully committed to an utterance. We adopted the framework of Morzycki (2011) for analyzing metalinguistic degree morphemes in terms of degrees of precision: a speaker using ...ish is being less than fully precise in making a claim. We then argued that imprecision is also at-issue for two other uses of the suffix form

26 Source: Wayne's World

27 It is difficult to evaluate what (36b) is telling us, since believe triggers neg-raising. 
of -ish, namely with temporal expressions like three o'clock, and with the somewhat marginal uses with minimum-standard gradable adjectives like bent.

This analysis raises several interesting questions that we hope will be addressed in future research. First, can the denominal use of -ish in (3) receive a unified analysis with the other uses? It is not clear to us whether it can, or even should. For example, childish does not seem to be used for an individual that could be counted as a child when used imprecisely. Rather, it indicates that an individual shares certain properties with a child. Furthermore, not all denominal uses share this characteristic. For instance bookish and stylish don't mean that an individual shares properties with a book or a style, respectively. Morris (1998) also notes that denominal -ish is not particularly productive, and that the forms that exist are somewhat idiosyncratic, further suggesting that a unified analysis may not be possible.

Second, there are several other linguistic expressions that appear at first blush to make a semantic contribution similar to ...ish/-ish. These include kinda and more or less, along with several other hedging expressions (Lakoff 1973). As our brief comparisons with sorta and German schon have shown, such expressions, although similar to ...ish/-ish, have slightly different distributions and uses, which ultimately require distinct analyses. This leads us to the question of what sorts of formal typologies may emerge when we take into account other hedges, as well as other potential candidates for metalinguistic degree morphemes.

Third, our analysis suggests a diachronic trajectory between the suffix -ish and metalinguistic ... ish whereby the latter takes on a flavor speaker-orientedness. This sort of diachronic path is consistent with the notion of subjectification in the literature on semantic change, whereby there is a tendency for linguistic items tend to acquire more speaker-oriented flavors over time (e.g., Traugott 1989, see Beltrama 2014 for recent discussion). Thus, we have identified another case where subjectification is implicated in semantic change, specifically in the context of degree modification.

Finally, as we have already indicated, there appears to be a non-trivial connection between metalinguistic degree morphemes and speaker-oriented meanings. This has led certain authors (Beltrama 2014; McCready \& Kaufmann 2013) to view certain precision-regulating devices as involving aspects of meaning located at the level of a conventional implicature, in the sense of Potts $(2005,2007)$. However, recall that there is at least some evidence (see (32)) that the contribution of ... ish can be directly challenged, which is not a characteristic property of conventional implicatures. This is the reason why we have not pursued an analysis of ...ish involving a conventional implicature. Nevertheless, the fact that it is difficult to embed ...ish under certain operators like negation and if indicates that ...ish shares at least some properties with other expressions that are analyzed as involving expressive meaning qua conventional implicature, so there still may be some deeper significance to this finding lurking behind the scenes here. 
Bochnak and Csipak

\section{References}

Anderson, Curt. 2013. Inherent and coerced gradability across categories: manipulating pragmatic halos with sorta. In Anca Chereches \& Todd Snider (eds.), Semantics and Linguistic Theory (SALT) 23, 81-96. Ithaca, NY: CLC Publications.

Beltrama, Andrea. 2014. From totally dark to totally old: The formal semantics of subjectification. Talk presented at Sinn und Bedeutung 19, September 16.

Cresswell, Max J. 1976. The semantics of degree. In Barbara Partee (ed.), Montague Grammar, 261-292. New York: Academic Press.

Cummins, Chris, Uli Sauerland \& Stephanie Solt. 2012. Granularity and scalar implicature in numerical expressions. Linguistics and Philosophy 35(2). 135169.

Giannakidou, Anastasia \& Melita Stavrou. 2009. On metalinguistic comparatives and negation in Greek. In Claire Halpert, Jeremy Hartman \& David Hill (eds.), 2007 Workshop on Greek Syntax and Semantics, 57-74. Cambridge, MA: MIT Working Papers in Linguistics.

Giannakidou, Anastasia \& Suwon Yoon. 2011. The subjective mode of comparison: Metalinguistic comparatives in Greek and Korean. Natural Language and Linguistic Theory 29. 621-655.

Grice, H. Paul. 1975. Logic and conversation. In Peter Cole \& Jerry L. Morgan (eds.), Syntax and Semantics, Vol. 3, Speech Acts, 41-58. New York: Academic Press.

Hamblin, Charles. 1973. Questions in Montague English. Foundations of Language 10. 41-53.

Heim, Irene. 2001. Degree operators and scope. In Caroline Féry \& Wolfgang Sternefeld (eds.), Audiatur Vox Sapientiae, 214-239. Berlin: Akademie-Verlag.

Horn, Laurence. 1989. A Natural History of Negation. Chicago: University of Chicago Press.

Kennedy, Christopher. 1997. Projecting the adjective: The syntax and semantics of gradability and comparison: University of California, Santa Cruz PhD dissertation.

Kennedy, Christopher. 2007. Vagueness and grammar: The semantics of relative and absolute gradable adjectives. Linguistics and Philosophy 30(1). 1-45. doi:10.1007/s10988-006-9008-0.

Kennedy, Christopher \& Louise McNally. 2005. Scale structure, degree modification and the semantics of gradable predicates. Language 81(2). 345-381. doi:10.1353/lan.2005.0071.

Krifka, Manfred. 2000. Alternatives for aspectual particles: Semantics of still and already. In 26th Annual Meeting of the Berkeley Linguistics Society: General 
A new metalinguistic degree morpheme

Session and Parasession on Aspect, 401-412. Berkeley: BLS.

Krifka, Manfred. 2009. Approximate interpretations of number words: A case for strategic communication. In Erhard Hinrichs \& John Nerbonne (eds.), Theory and Evidence in Semantics, 109-132. Stanford, CA: CSLI Publications.

Kuzmack, Stefanie. 2007. Ish: A new case of antigrammaticalization. Talk presented at Linguistic Society of America Annual Meeting, January 4.

Lakoff, George. 1973. Hedges: A study in meaning criteria and the logic of fuzzy concepts. Journal of Philosophical Logic 2(4). 458-508.

Lasersohn, Peter. 1999. Pragmatic halos. Language 75(3). 522-551.

Lasersohn, Peter. 2005. Context dependence, disagreement, and predicates of personal taste. Linguistics and Philosophy 28(6). 643-686. doi:10.1007/s10988005-0596-x.

McCawley, James. 1998. The Syntactic Phenomena of English. Chicago: University of Chicago Press.

McCready, Eric \& Magdalena Kaufmann. 2013. Maximum intensity. Ms. Aoyama Gakuin University and University of Connecticut.

Morris, Lori. 1998. A toughish problem: The meaning of -ish. In LACUS Forum 24, 207-215. Toronto: Linguistic Association of Canada and the United States.

Morzycki, Marcin. 2011. Metalinguistic comparison in an alternative semantics for imprecision. Natural Language Semantics 19(1). 39-86.

Morzycki, Marcin. 2012. The several faces of adnominal degree modification. In Jaehoon Choi, E. Alan Hogue, Jeffrey Punske, Deniz Tat, Jessamyn Schertz \& Alex Trueman (eds.), WCCFL 29, 187-195. Somerville, MA: Cascadilla Proceedings Project.

Norde, Muriel. 2009. Degrammaticalization. New York: Oxford University Press.

Potts, Christopher. 2005. The Logic of Conventional Implicature. Oxford: Oxford University Press.

Potts, Christopher. 2007. The expressive dimension. Theoretical Linguistics 33. 165-198.

Rooth, Mats. 1992. A theory of focus interpretation. Natural Language Semantics 1(1). 75-116.

Rotstein, Carmen \& Yoad Winter. 2004. Total adjectives vs. partial adjectives: Scale structure and higher-order modifiers. Natural Language Semantics 12(3). 259-288. doi:10.1023/B:NALS.0000034517.56898.9a.

Rullmann, Hotze. 1995. Maximality in the semantics of wh-constructions: University of Massachusetts, Amherst PhD dissertation.

Schwarzschild, Roger. 2008. The semantics of comparatives and other degree constructions. Language and Linguistic Compass 2(2). 308-331.

von Stechow, Arnim. 1984. Comparing semantic theories of comparison. Journal of Semantics 3. 1-77. doi:10.1093/jos/3.1-2.1. 
Stephenson, Tamina. 2007. Judge dependence, epistemic modals, and predicates of personal taste. Linguistics and Philosophy 30(4). 487-525. doi:10.1007/s10988008-9023-4.

Sugawara, Ayaka. 2012. Semantics of English suffix -ish. Paper presented at CLS 48.

Traugott, Elizabeth. 1989. On the rise of epistemic meanings in English: An example of subjectification in semantic change. Language 65. 31-55.

Villalta, Elisabeth. 2008. Mood and gradability: an investigation of the subjective mood in Spanish. Linguistics and Philosophy 31. 467-522.

Zimmermann, Malte. 2014. Wird schon stimmen! A unified analysis of modal and aspectual 'schon' as scale aligners. Handout from talk at DGfS, March 5.

M. Ryan Bochnak

Department of Linguistics

1203 Dwinelle Hall

University of California, Berkeley

Berkeley, CA 94720-2650

USA

bochnak@berkeley.edu
Eva Csipak

Seminar für Englische Philologie

Georg-August-Universität Göttingen

Käte-Hamburger-Weg 3

37083 Göttingen

Germany

ecsipak@gwdg.de 